\title{
In-Company Training In Tourism: The Case of the Domotel Hotels and Resorts
}

\author{
Vasiliki Brinia (Corresponding author) \\ Athens University of Economics and Business, Greece \\ Email: vbjournal@hotmail.com \\ Klepkou Chryssi-Alexandra \\ Hellenic Open University, Greece
}

Received: February 09, 2016 Accepted: February 18, 2016 Published: April 04, 2016

doi:10.5296/ijhrs.v6i2.9258 URL: http://dx.doi.org/10.5296/ijhrs.v6i2.9258

\begin{abstract}
The purpose of this research is to investigate the DOMOTEL group of companies, on planning, organization and management of the Domotel internal academy programs as well as the results of the in-company training. The type of this research is the case study, and the data have been processed by the method of content analysis. It was found that the in-house Domotel Academy programs are designed, organized and evaluated through specific procedures. The education and training of employees is under the responsibility of the company whose aim and purpose is the continuous training of the workforce, the performance improvement and the compliance with the labor standards of the Domotel group of companies which consequently will lead to profitability. The originality of the research lies in the fact that the research in the tourism sector which engages the in-company training is little.
\end{abstract}

Keywords: In house training, Planning, Organizing, Management, Trainers, Trainees, Results 


\section{Introduction}

Continuing education and training are the result of the urgent need for lifelong learning. Economic developments did not leave Europe indifferent. Technology, information and lifelong learning will play an important role in giving equal opportunities to every citizen. The European Council decides that Europe should create new opportunities for learning by creating learning structures for all people in order to meet the new requirements (Sipitanou, 2014). In this context the in-company training programs are also included. Their objectives should be to increase the employability of the workforce, to improve the competitiveness of businesses and to facilitate the access to skills improvement programs (Prokou, 2009).

In tourism the skills of employees is what matters the most, as the level of the provided service is offered in conjunction with them. Knowledge and skills are the attributes that keeps the hotels' sustainability. Therefore, staff training is necessary for many reasons but mainly it increases the productivity as workers are provided with professional knowledge and experience. Furthermore, vocational education motivates and inspires employees by providing them with all the necessary information and by helping them realize how important their work is (Wang, 2008 op. Ref. In Singh, 2014). Hotels with profitability always include plan for staff training in their development.

The purpose of this research is to investigate the programs' planning, organization and management in the internal academy of Domotel programs. The research questions are: how the in-house training programs of Domotel are designed, organized and managed.

\section{Theoretical Part}

According to Chitiris (2001) the companies ensure that products and services are always competitive and, therefore, the companies can be financially healthy. Appropriate human resources are the key ingredient for achieving success. Given the rapid social and technological changes of modern business society, human resources must be constantly trained in order to be able to succeed. The complexity of work in business requires new knowledge, skills and qualifications of employees. The in-company training is the framework through which workers can be equipped appropriately.

According to Gkagialis (2008) and Sotiroudas (2012), the "in-company training" is the process of education provided by a company to old and young workers through a series of seminars and training programs. The training is divided into training at work (on the job training) which is usually in the employee's workplace using equipment, machinery or tools that he/she uses. Off the job training is not carried out in the workplace, but on a specific training area equipped with appropriate means (Valkanos \& Frangoulis, 2009).

It is indeed a fact that in recent years more and more companies seek the vocational training of their employees. According to Cedefop (2010) «everybody considers continuous training, especially the training which is provided by employers, as something good, if not essential. According to surveys, it can increase productivity and encourage innovation, thus improving the competitiveness, market share and profitability". 


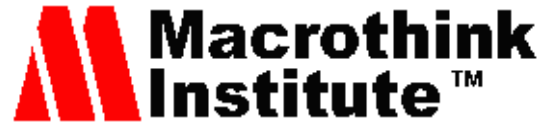

International Journal of Human Resource Studies

ISSN 2162-3058

2016, Vol. 6, No. 2

The benefits of employee training are many and in many cases they have been recorded in practice. Firstly, workers acquire skills and strengthen their position. Their training makes them more productive and more competitive on the labor market (Tsaoulis). At the same time workers have the feeling that their company "cares", wants them to be better, helps them to develop and acquire new knowledge and skills, boosts their self-esteem and improves their behavior. Staff training also supports the formation of corporate culture, which may enhance the implementation of the values and business objectives (Gkagialis, 2008).

In summary, the professional training of workers is not a responsibility but a process that should be now considered routine for any business. With the rapid development of technology and science, the modern citizen-workers cannot remain isolated in old education standards; they need to modernize and acquire new knowledge and skills that will guarantee them a place in global market.

\section{Research Part}

\subsection{Purpose}

The in-company training and design of educational programs created the need for investigating the Domotel group of companies that uses training programs for the training of staff. Therefore, the aim of this research is to investigate the views of stakeholders and learners of Domotel on planning, organization and management of the programs of the Domotel training academy.

\section{Methodology}

This research used the method of case study. According to Robson (2010) the case study is a type of qualitative research that studies a situation, an individual or a group that we are interested to look at. In qualitative research, the intention is not to generalize the results, but explore the way in which the investigation of a central phenomenon evolves (Creswell, 2011). In this research, we try to explore the views of trainers and trainees of Domotel on designing, organizing and managing its training programs. This qualitative survey was conducted by interviews.

The advantage of the case study is that it typically investigates a modern phenomenon; a social phenomenon that is evolving and must be examined in detail in its own environment. It helps not only in the description but also in discovery of true data and the interpretation of complex matters of everyday life (Zaidah, 2007).

\section{Sample / Research Tool}

The workforce of the "Les Lazaristes" hotel in Thessaloniki belonging to the Domotel group of companies was chosen as the sample for this research. The target population were the trainers and trainees of the academy. The sample selection was intentional sampling and sampling with particular "critical sample» (Robson, 2010). In intentional sampling the researcher chooses intentionally individuals and location to learn and understand the central phenomenon (Creswell, 2011). This sample makes it possible to meet specific needs such as in this research. 
Nine (9) people participated in this research. According to Creswell (2011) usually in the qualitative method research, a small number of participants is selected, in order for the researchers to use of the results in a more efficient way.

The semi-structured interviews were selected as the main research tool. There were three groups of interviewees: academy stakeholders, trainers and trainees. There were three participants from each target group. To ensure the reliability of the tool and the validity of the research, we conducted a pilot implementation of the interview in a very small sample size (2 people), who did not participate in the final survey (Robson, 2010). The pilot interviews were a test of the questions and the expected answers, in order to increase the reliability of the tool (Robson, 2010).

\section{Results}

\subsection{Domotel Hotel}

Domotel (www.domotel.gr) is a member of the group "DOMOTECHNIKI SA", which firstly appears in 2004. Domotel stars in the field of luxury hospitality and fulfills the expectations and demands of all customers. Domotel, through the philosophy of offering integrated hosting services, evolves constantly by renewing its infrastructure and upgrading the level of services.

\subsection{Creation of the Domotel Academy}

Domotel foresees the developments in the modern world of business and the increasing competition in the hotel sector. However, it also notices deficiencies in knowledge, skills and competencies of its human resources. Therefore, it decided to create an internal staff training program, named Domotel academy.

\subsection{Planning, Organization and Management of Domotel Academy programs}

\subsubsection{Educational Material Development}

The initial training material is the content of Domotel training manuals, prepared by the Director of the Academy. Both Domotel trainers and on the job trainers enrich, update and expand this educational material with new sources. Any new material may come from books, internet, own writing, it should be delivered in electronic form (pages from books) and in manuals to the Secretariat. The Secretariat in turn notifies all the new material to the Director of the Academy and the Managers of Hotels, in order to be confirmed. Within a reasonable time they confirm the new material and they initiate the update of the Domotel training manuals.

\subsubsection{Domotel Trainer and On the Job Trainer}

The Domotel Trainer can be an employee or head of a department or even a hotel manager of the company. The trainer must have a university degree in combination with at least 5 years of professional experience. Where appropriate, the trainer may have lower academic degree, but with a 10-year minimum work experience; experience as a professor in tourism - hotel school or in a vocational training school is a powerful additional qualification. In any case, 
the trainer should have attended the "train the trainer" program by the Director of the Academy or by an external agency and he/she must be certified accordingly.

The Domotel Trainer is responsible for the preparation and implementation of the in-company training, under the supervision of the Academy Director and the hotel directors. $\mathrm{He} / \mathrm{she}$ also organizes and enriches the educational material. In some courses the Domotel trainer cooperates with on the job trainers, but he/she keeps the overall responsibility of the program. The On the Job Trainer is the main partner of the Domotel Trainer in order to perform intra-company training in practical aspects of the subject. The main difference is that while the Domotel Trainer does class courses (seminar character), the On the Job Trainer, makes practical training in the workplace rather than seminars.

\subsubsection{Planning and Organization}

In the first days of December of each year, the annual training program for next year is established, under the responsibility of the Director of Internal Academy in collaboration with the Hotel Managers, following suggestions of the heads of departments. The proposal is approved as it is or changes are made by the CEO of the company and are notified to the managers of the hotels, to the trainers and to the secretaries. In any case, to finalize this set of data many aspects are taken into account, such as the annual and semi-annual reviews of the staff, the proposals / recommendations of the heads and directors, and unexpected projects that can be included.

The secretaries of hotels, in collaboration with the Director of the Academy, confirm in the first half of each month, the exact dates and other details (trainer, participants, days and hours in, title, material etc) of the training of the next month. This information is transferred to managers and supervisors, in order to communicate them to their staff. Two weeks before conducting the training, all participants are reached and updated with all the details of training by the secretaries. The participants are invited to acquire their training manuals. In the same time (two weeks before training) the Domotel Trainers in cooperation with the On the Job Trainers, deliver to the secretariat any additional material for the training, which shall be notified directly to the Director of the Academy for approval and confirmation. A week before the training any exercises should be prepared, along with other educational material and evaluation sheets. At the end of the program, the evaluation sheets should be gathered by the trainer and handed over to the Secretariat. All these are kept in the appropriate file regarding training evaluations.

\subsubsection{Assessment}

The Domotel Academy is evaluated at three levels through three different evaluation sheets. The educational process is firstly assessed by the participants in each training program (either on the job or seminar type) through evaluation sheet, which is completed at the end of each training session. The sheets are collected by the trainer and are delivered the same day in a sealed envelope, to the secretariat. The trainer, within one week of the completion of training, is invited to fill in the course evaluation sheet, which is submitted to the Secretariat, and later notified to the Director of the Academy. 
Finally, the Director of the Academy completes an evaluation sheet, after the observation of the teaching of each instructor (Domotel Trainer and On the Job Trainer) and the examination of educational and supervisory material. These evaluation sheets will be delivered to the secretariat to be filed accordingly and be labeled by training and instructor.

\subsubsection{Content/Topics of training}

The Domotel Academy covers a wide agenda that can support the entire operation of the Domotel company. More specifically, there are courses for all operating departments and specialties: reception, service, food and beverage and housekeeping. There is also a customer service program at two levels (I and II) and an introductory training program (induction training) for new employees. Finally, there is a variety of specific topics covering issues like: sales, training of trainers, administrative capacity, food safety and hygiene, fire safety, first aid etc. Apart from the latter, whose seminars take place in cooperation with external partners and suppliers, all the other issues, are covered internally by the Domotel Trainers and the Director of the Academy.

\section{Conclusions}

Following the research process of this study, the conclusions for the internal academy of the Domotel group are related to the planning, organization and management of training programs which are offered to the workforce. The program design comes after careful study of the needs which generally arise in the area of customer service. More specifically, the design stems from studying the group's needs which are mainly the compliance with the set standards and their implementation by workers in the area of customer service. The purpose of the group is the uniformity in implementing procedures followed by all employees in all the available hotels.

Regarding the organization of the programs, the group begins with the selection of internal trainers relying on specific characteristics related to the skills and knowledge which are required by a trainer. Then it trains the trainer so that he/she can meet the demands of the new role and to carry out training seminars with expertise. The organization also includes the selection of the location and duration of the programs. It is found that in the field of hotels, the training is mainly on the job training, because the nature and place of work are important for practice (customer service, housekeeping). In the few cases where the presentation or lecture are selected to enrich knowledge of learners from a theoretical viewpoint, trainers chose modern and appropriate teaching tools (computers, projectors, etc).

The management of the training programs of Domotel group starts with the administrative support that is considered an important part as it is necessary for coordination. Informing trainers, learners and training managers is made by the administrative and secretarial support. The financial support is also important and it worth mentioning that Domotel finances educational programs mainly from its own resources. Finally, the monitoring and the evaluation of programs are made by training managers and more specifically by the director of the academy. The evaluation is carried out in trainers, trainees and managers. Thus data collection is more objective and results can be used for future use. 


\section{Al Macrothink Institute ${ }^{\mathrm{TM}}$}

The practical implementation of this research in society and science is that it triggers further exploration in this area as there is no information on specific programs that may be implemented in other companies. Furthermore, it provides information on in-house projects of a major hotel group. The small sample is a limitation of the research; therefore, the results cannot be generalized to the wider population. The limited number of employee participation in the survey because of the workload was another constraint.

The findings showed that the creation of the Domotel academy offers continuing training for human resources. With the latest developments, training is now an essential element for any business that wants to be considered able to meet the requirements of the new competitive business society. Employees are an important asset. Maintaining and enhancing their knowledge, skills and abilities in order to overcome any obstacles that may occur is essential. Quality in management and training in the field of customer service will result in improved employee performance and it will increase the company's profit.

\section{References}

\section{Greek}

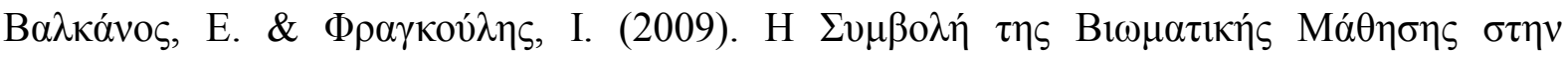

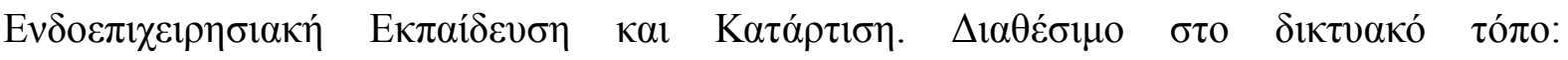
http://edu4adults.blogspot.com/2010/09/blogpost_16.html\#ixzz1sKgDrXmE (10/5/2015).

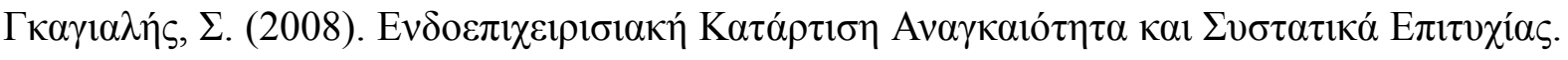

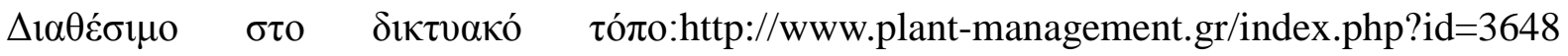
(9/5/2015).

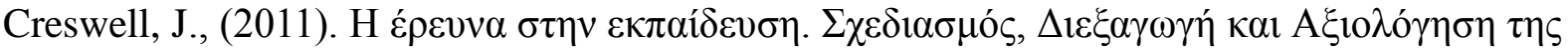

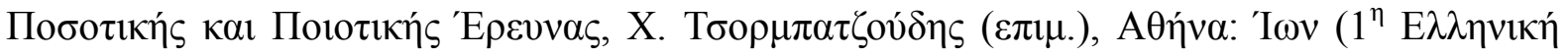

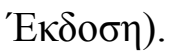

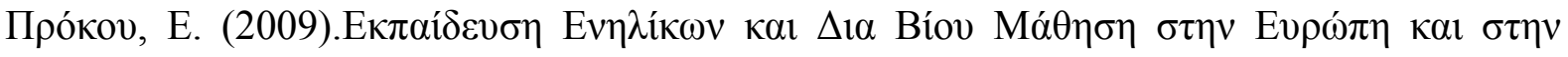

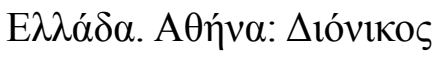

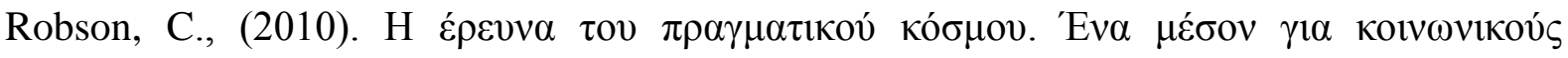

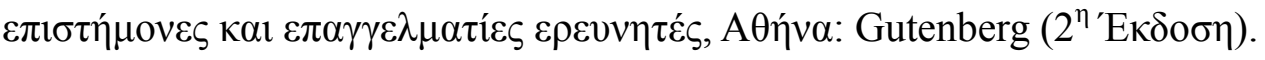

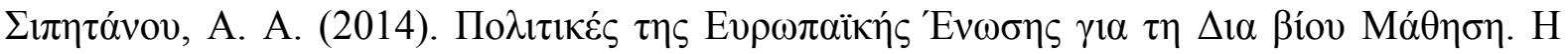

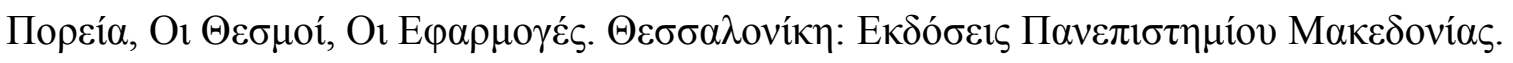

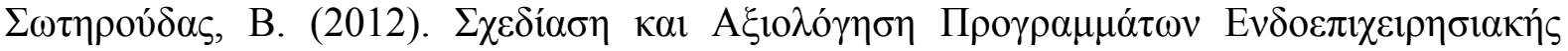

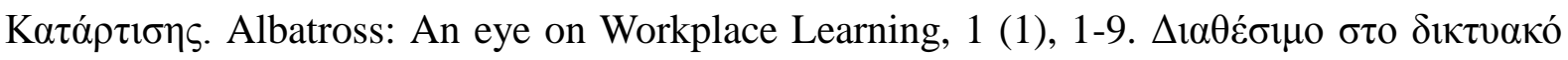

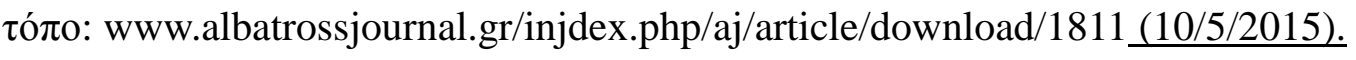

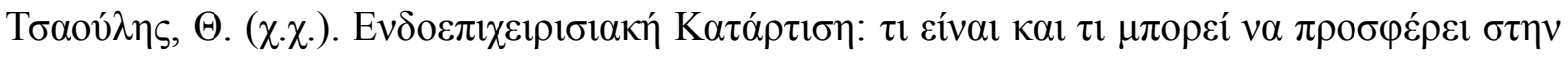

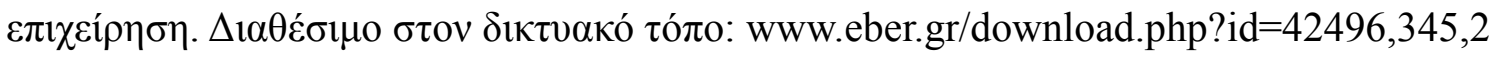

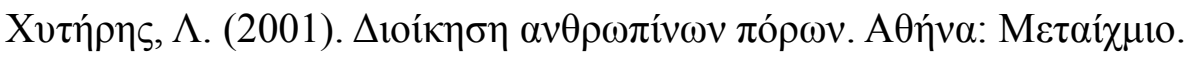




\section{English}

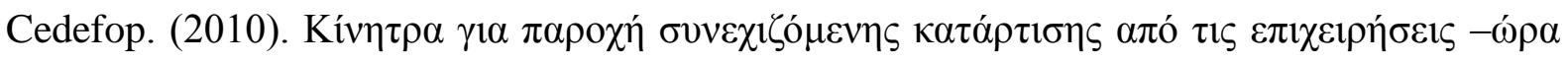

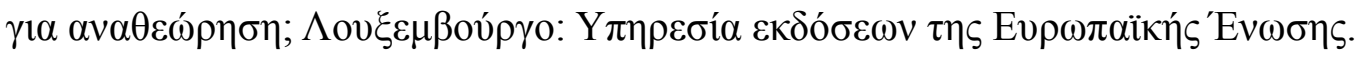

Singh, A. (2014). Emergence of Training Program in Small Scale Hotels in Punjab Region of

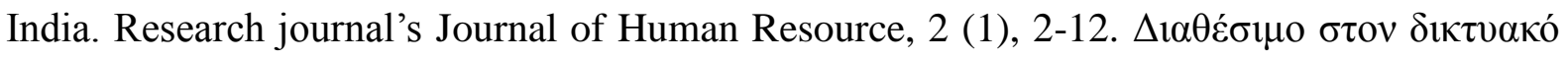

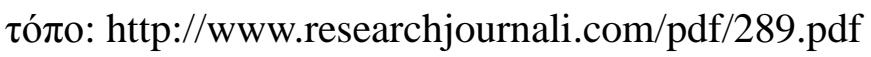

Zaidah, Z. (2007). Case study as a research method. Jurnal Kemanusiaan $9 \Delta$ $\alpha \theta \varepsilon \dot{\sigma} \not \mu o ~ \sigma \tau o v$

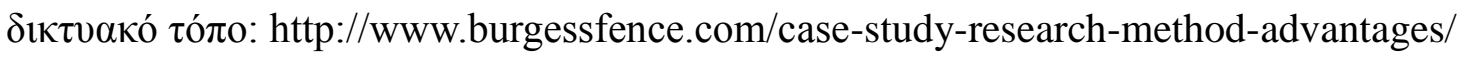

\section{Copyright Disclaimer}

Copyright for this article is retained by the author(s), with first publication rights granted to the journal.

This is an open-access article distributed under the terms and conditions of the Creative Commons Attribution license (http://creativecommons.org/licenses/by/3.0/). 